\section{Analysis of Power System and Drivetrain Component Design for Toyota Calya Electric Car}

\author{
Putri Nabila Auliya, I Nyoman Sutantra \\ Department of Mechanical Engineering, Institut Teknologi Sepuluh Nopember, Surabaya 60111, Indonesia \\ Received: 5 February 2020, Revised: 4 September 2020, Accepted: 10 September 2020
}

\begin{abstract}
The development of science and technology in automotive field increases as the time went by. The conventional vehicle nowadays has a negative impact on the environment, for example gas emmisions. To cope with the impact the innovation in electric vehicle (EV) is needed. In this research, there are three stages obtain a desired outcome: the data collection stage, the calculation stage, and the analysis stage. For the data collection, there are two methods; the experimental and the simulation stage. For the experimental, dynotest needs to be performed, while in the simulation is to obtain the data generated by Solidwork. In the calculation stage, the maximum speed, traction force, power generated, energy consumption, energy requirement, and slip and skid speed were calculated to obtain the desireable performance. Then, the analysis was performed to compare the performance of ICE and designed BEV and comply with the theories. The results from this research for converting ICE to BEV are re-design of the transmission and replace the engine into BLDC motor. The transmission needed for BEV is two-speed transmission while the motor used is $60 \mathrm{~kW}$ BLDC motor. The BEV can performs maximum climb-ability of $30^{\circ}$ and reaches the maximum speed of $136 \mathrm{~km} / \mathrm{h}$ in flat road while ICE only have climb-ability of $30^{\circ}$ and same maximum speed as BEV. The energy consumption of BEV is $0.431 \mathrm{~kW} . \mathrm{h} / \mathrm{km}$ while ICE version is $0.539 \mathrm{~kW} . \mathrm{h} / \mathrm{km}$. The battery used is Li-ion Ploymer $39 \mathrm{~kW} . \mathrm{h}$ due to better specific energy and less toxic. For turning behavior, ICE have the safer driving behavior due to the center of gravity and understeer tendency than BEV. But the BEV still save to drive in certain turning speed.
\end{abstract}

Keywords: Electric vehicle, energy consumption, stability, center of gravity

\section{Introduction}

The development of technology and science enables humans to do various things easily. In order to make fast mobility happen, the use of conventional vehicles becomes a solution and increase by the time went by. Based on Badan Pusat Statistik Indonesia, there were 146.858.759 vehicles in 2018 [1]. One of the most used vehicle based on GAIKINDO 2019 comes from Toyota Calya. The number of vehicles increase $\mathrm{CO} 2$ emissions in the free-air due to gasoline. Quoted by Enerdata 2018, there were 130.68 MtCO2 from transportation sector in 2017 [2]. The impact of using conventional vehicle (internal combustion vehicle or ICE) to our living made the government issue (Peraturan Presiden no. 55 of year 2019) to accelerate the battery electric vehicle (BEV) development.

Electricity is the product of renewable energy that can be applied in various fields, especially electric vehicle. The existence of electric vehicles can reduce the impact of fueled vehicles usage. However, there are limitations in electric energy application. For the example the performance of electric vehicles that is not comparable enough to compete with the ICE vehicle performance such as drive- ability and mileage.

Needs of eco-friendly technology to reduce gas emissions lead to the development of electric vehicle technology. This is a challenge for engineers to create sustainable green technology that can be applied for automotive industry. The engineers also should concern with the costs and process due to give affordable, convenient, and efficient EV for the users. In this study, a 2019 Toyota Calya type $\mathrm{E} \mathrm{M} / \mathrm{T}$ was re-designed with repalcing the engine to the electric motor and reducing its transmission level. After determine the specific electric motor and transmission ratio used, the analysis of traction and power performance, energy consumption, battery energy requirements, and vehicle turning behavior based on slip and skid generated can be obtain based on calculation.

\section{Experimental, Simulation, and Theoreti- cal Method}

\subsection{Experimental Method}

In the data collection stage, a dynotest test was performed on a Toyota Calya $\mathrm{M} / \mathrm{T}$ vehicle. The chassis dynotest was performed in the highest gear to determine

*Corresponding author. Email: sutantra@me.its.ac.id 
the value of torque and power at the highest speed for each of six tests. The dynotest was held at the GUT Motorsport Klampis workshop, Surabaya. Here the results of chassis dynotest obtained shown in the Figure 1 .

The average torque and power values from six tests used to calculate the performance of Toyota Calya Internal Combustion Engine (ICE) vehicle. It's obtained from the traction force value to calculate the maximum slope angle and maximum speed. This results be the reference for the Toyota Calya Battery Electric Vehicle (BEV) design.

\subsection{Simulation Method}

In order to get the exact resistive force, the drag coefficient needed. In this simulation method, Solidworks used to generate the drag coefficient value for the specific vehicle. First of all the Toyota Calya M/T vehicle modelled to have the exact dimension and shape. Then, using Solidworks Sim Flow to generate the drag coefficient simulation with variations in speed of $30 \mathrm{~m} / \mathrm{s}, 35 \mathrm{~m} / \mathrm{s}, 40 \mathrm{~m} / \mathrm{s}$, $45 \mathrm{~m} / \mathrm{s}$, and $50 \mathrm{~m} / \mathrm{s}$. Using Solidwoks fluid simulation, the coefficient drag value can be obtained at the certain velocity as shown in Figure 2 .

After the simulation, the average value of Toyota Calya drag coefficient obtained is 0.5 . This value is acceptable because based on the study of vehicle drag coefficient, the van or seven-seated model has the value of 0.5 until 0.7 [3]. So this value can used for the next calculation.

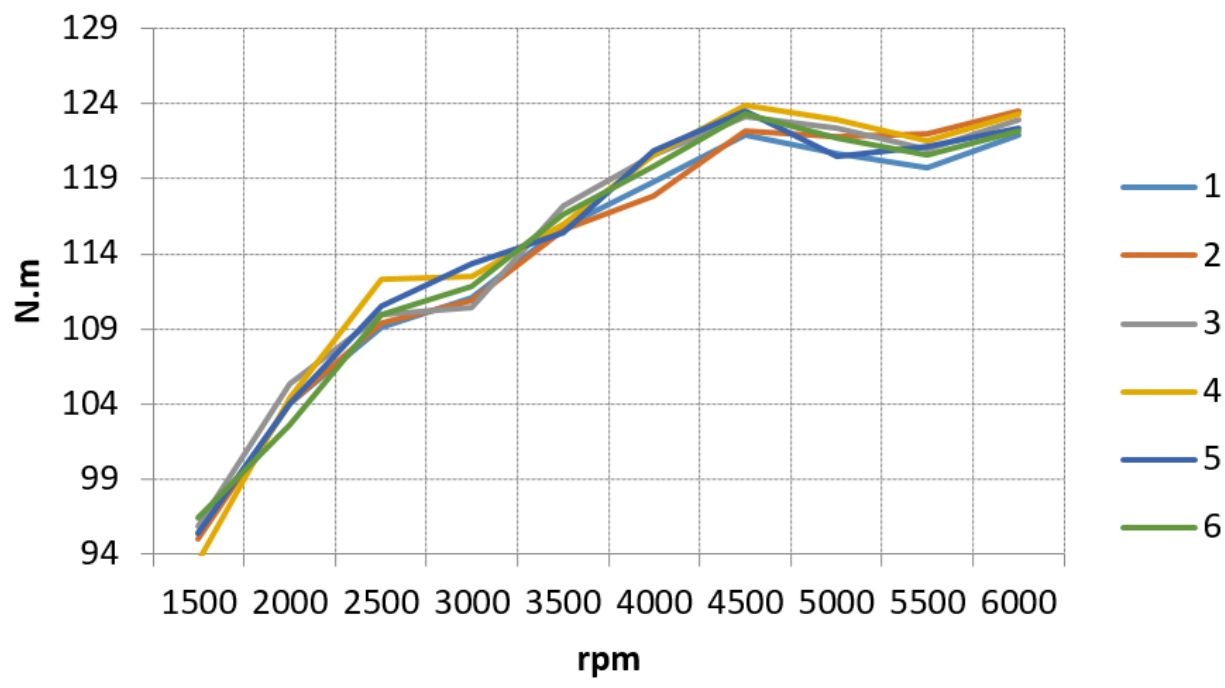

(a)

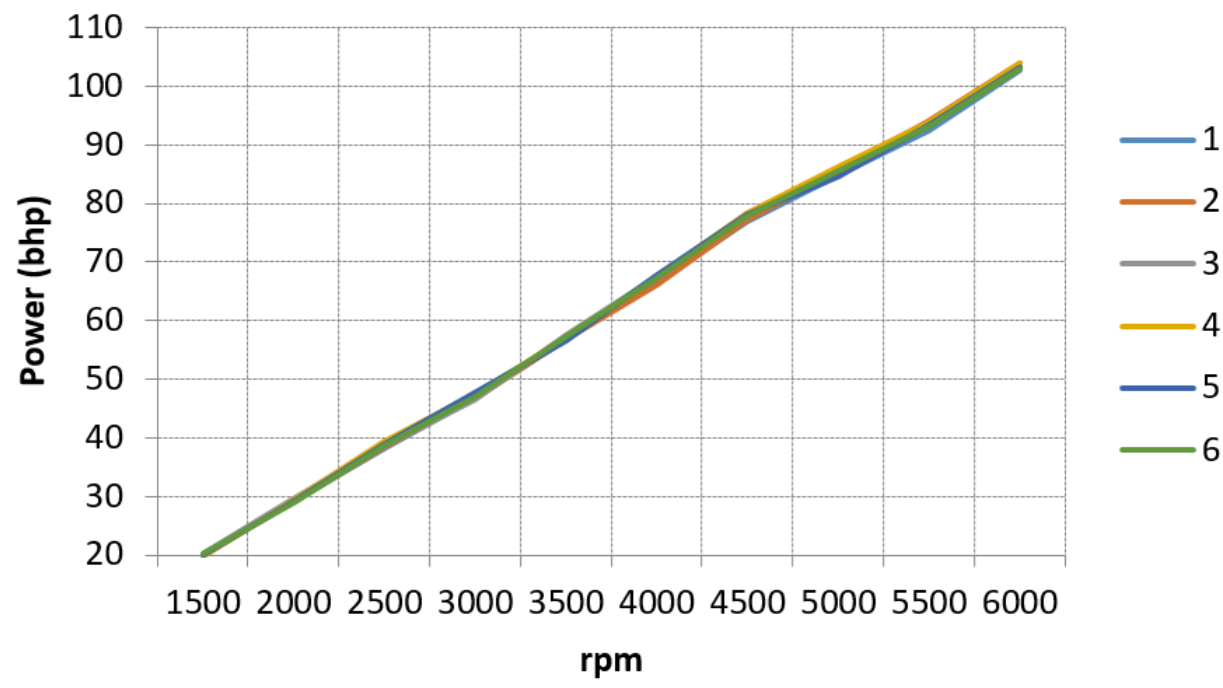

(b)

Figure 1. Toyota Calya chassis dynotest results on (a) torque (b) power performance 


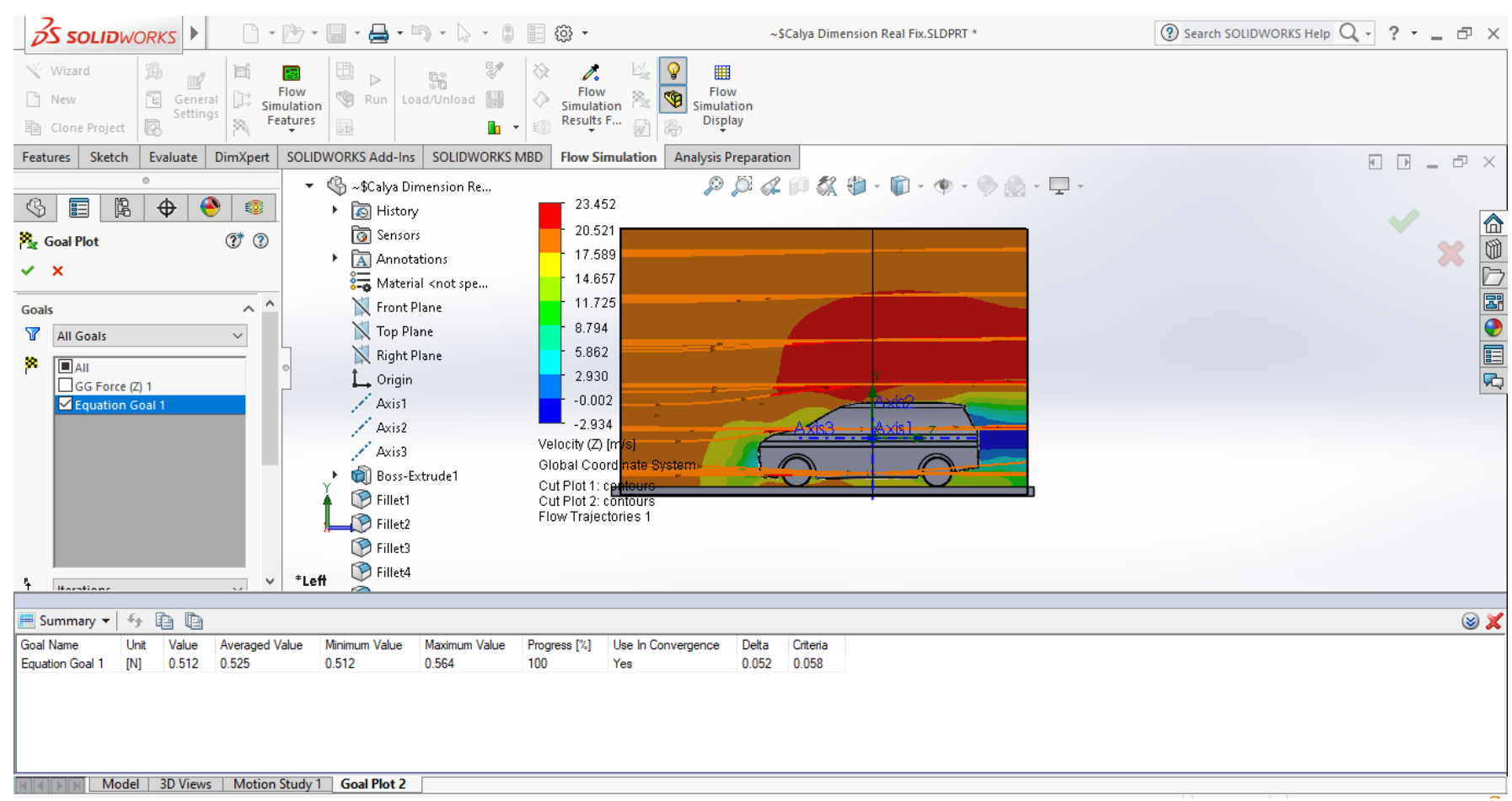

Figure 2. The Drag Coefficient Simulation using Solidworks

\subsection{Theoretical Method}

\subsubsection{Energy, Power, and Traction Calculation}

In the theoretical method, the calculation was performed to obtain the value of resistive forces, traction, power, energy consumption, battery power requirements, center of mass, slip angle, and skid speed based on the reference. First thing to do is to calculate the vehicle resistive forces that occurs on the vehicle [3]. The total resistive force is summation of aerodynamic force, rolling resistant force, and gradient force. calculate the value total resistive force, the equation can be written as:

$$
F_{r}=R_{r}+R_{a}+R_{g}
$$

$$
\begin{gathered}
F_{r}=\left(f_{r} \times W \times \cos \theta\right)+\left(\frac{1}{2} \times C_{d} \times \rho \times V_{a}^{2} \times A_{f}\right) \\
+(W \times \sin \theta) \\
f_{r}=f_{o}+f_{s}\left(\frac{V}{100}\right)^{2,5}
\end{gathered}
$$

where $\rho$ is the air density, $C_{d}$ is the coefficient of drag, $A_{f}$ is the frontal area of the vehicle, $V$ is the speed of the wind relative to the vehicle. While for the rolling resistant foce, $f_{r}$, is the rolling resistance coefficient, $\theta$ is the angle of slope of the vehicle, $f_{o}$ and $f_{s}$ are the coefficient of which the values depend on the tire pressure, and $W$ is the vehicle weight.

After obtaining the total drag force of the vehicle, the power needed by the vehicle will be calculated based on the total resistive force as in Equation 4 [4].

$$
P_{r}=F_{r} \times V_{k}
$$

This value is the amout of power needed to reach the maximum speed at the horizontal slope angle. After obtaining the resistive power value, the minimum power required for the electric motor is calculated using Equation 5.

$$
P_{m}=\frac{P_{r}}{\eta_{t}}
$$

where $\eta_{t}$ is transmission efficiency. To find the traction and power characteristics, it is necessary to use a transmission ratio to achieve maximum speed and angle of slope. The vehicle transmission ratio can be determined with Equation 6.

$$
i_{n}=\frac{F_{r} \times R}{T_{m \max } \times i_{g} \times \eta_{t}}
$$

where $F_{t}$ is drag, $R$ is wheel radius, $i_{g}$ is final drive (axle) ratio, and $T_{m \text { max }}$ is maximum electric motor torque. Then to find the linear speed and traction force for each rotation speed of each transmission ratio, it can be found by using Equations 7 and 8 [5].

$$
\begin{gathered}
V_{n}=\frac{\pi \times R \times N_{b}}{30 \times i_{t n} \times i_{g}} \\
F_{t n}=\frac{I_{t n} \times I_{g} \times T_{m n}}{R} \cdot E_{d t}
\end{gathered}
$$

Where $V_{n}$ is the speed of the vehicle at each transmission ratio and $F_{t}$ is the traction force value that can be 
provided by the vehicle at each transmission ratio level. After the value of the traction force obtained, the power transmission, $P_{t}$, can be calculated for each level using the transmission power equation, as in Equation 9

$$
P_{t}=F_{t} \times V_{k}
$$

From the results, the traction and power characteristics of each transmission level are obtained. The value of the maximum speed at a certain slope and the climbability for each transmission level can be determined by plotting each the value.

For calculating the battery energy needed, the EV energy consumption must be known in order to know the amount of energy used while driving. Driving cycle is a series of data that describes the relationship between vehicle speed and driving time to shows the vehicle performance including energy consumption. In this study, the WLTP (World Harmonized Light-duty Vehicle Test Procedure) driving cycle is used because it provides a driving cycle with the closer test results to the real situation. The selection of the WLTP driving cycle class can be determined using Equation 10 [4].

$$
P M R=\frac{\text { Power }}{\text { Curb mass }}
$$

where the $P M R$ value is more than equal to 22 for class 1, $P M R$ values between 22 to 34 for class 2 , and $P M R$ is more than 34 for class 3 . After determine the driving cycle class, the amount of force applied, $F_{t o t}$, and the power given, $R H P_{p}$, when passing a certain speed calculated using Equations 11 and 12 [5].

$$
\begin{gathered}
F_{t o t}=F_{r}+F_{i}=\left(R_{a}+R_{r}+R_{g}\right)+(m \times a) \\
R H P_{p}=F_{t o t} \times v_{k}
\end{gathered}
$$

From the result from each point, a separation is made between the acceleration power and the brake power. So the power for accelerating only is obtained.

Energy is an integral function of power over time. The energy consumption value, $E_{p}$, for accelerating in one driving cycle calculated using the trapezodial integation approach of power as the following equation.

$$
\begin{aligned}
E_{p} & =\int R H P_{p} \times d t \\
& =\frac{\Delta x}{2}\left[R H P_{0}+2 R H P_{1}+\cdots+2 R H P_{n-1}+R H P_{n}\right]
\end{aligned}
$$

where the value of $\Delta x$ is the difference between the upper limit divided by the number of $n\left(\frac{b-a}{n}\right)$. The trapezodial method applied because the driving cycle data was assumed as linear function.

Vehicle has efficiency for each components of the power that makes the number of energy required become larger. While driving, the energy used to accelerate is calculated by Equation 14 [4].

$$
E_{c}=\frac{E_{p}}{\eta_{f t} \times \eta_{f m}} \times \frac{1}{\eta_{p f c} \times \eta_{f b}}
$$

where $\eta_{f t}$ is the transmission efficiency, $\eta_{f m}$ is the motor efficiency, $\eta_{p f c}$ is the power control efficiency, and $\eta_{f b}$ is the battery efficiency. Then the mileage can be reached by the EV, $s$, is calculated for one driving cycle using the following equation.

$$
s=(v \times t)+\frac{\left(a \times t^{2}\right)}{2}
$$

Then the battery requirements are calculated according to the desired mileage. Using the consumption values obtained, the minimum energy of the battery, $E_{b p}$, is obtained with the following equation:

$$
E_{b p}=d_{v} \times F E
$$

where $d_{v}$ is the cruising range covered during acceleration and $F E$ is energy consumption. To select a battery, a voltage (V) and capacity (A.h) value is required according to the motor used to avoid overheating during driving mode.

\subsubsection{Turning Behavior Calculation}

To deterime the turning behavior of a vehicle, a center of mass value based on the load of each components and its placement is needed using the basic moment. To simplify the study, we assume vehicle turning behavior follows the ideal situation called Anckerman's ideal turning radius to obtain the components needed for calculating as shown in Figure 3 


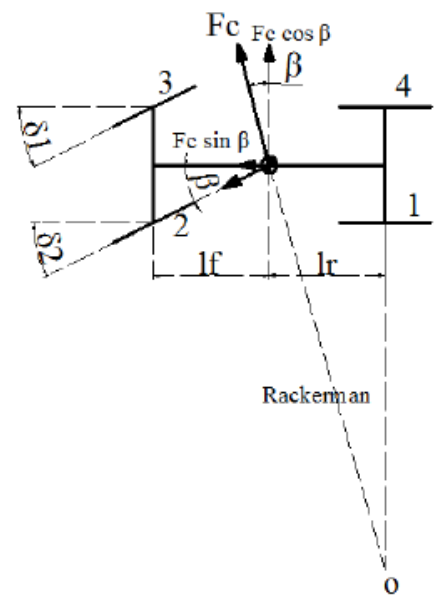

Figure 3. Anckerman's radius and turning corner [3]

After obtaining the center of mass for two type of vehicle, the turning behavior is calculated with Anckerman's ideal turning radius as the following equation.

$$
\begin{gathered}
R_{\text {anckerman }}=\frac{l_{f}+l_{r}}{\delta_{f}} 57,29 \\
\beta=\operatorname{arcs} \sin \left(\frac{l_{r}}{R_{\text {anckerman }}}\right)
\end{gathered}
$$

Using Anckerman's ideal radius value, the maximum speed of the skid vehicle is carried out for front wheel $\left(V_{s f}\right)$ and rear wheel $\left(V_{s r}\right)$ as following relations.

$$
\begin{gathered}
V_{s f}=\sqrt{\frac{R \cdot g}{W}\left[\frac{\mu \cdot l_{r} W}{l_{r} \cdot(\cos \beta \cdot)-h \cdot \mu \cdot \sin \beta}\right]} \\
V_{s r}=\sqrt{\frac{R \cdot g}{W}\left[\frac{\mu \cdot l_{f} W}{l_{f} \cdot(\cos \beta)-h \cdot \mu \cdot \sin \beta}\right]}
\end{gathered}
$$

Based on the maximum speed value for the skid, the turning behavior of the vehicle is known under the following conditions:

(a) $V_{s f}>V_{s r}$, when the rear wheel skid occurs before the front wheel skid and tends to oversteer.

(b) $V_{s f}<V_{s r}$, when the front wheel skid occurs before the rear wheel skid and tends to understeer.

Meanwhile, the value of the slip angle $\left(\alpha_{i}\right)$ that occurs on each wheel can be calculated using the following mathematical form.

$$
\begin{array}{r}
\alpha_{i}=0,3 \frac{C_{r p}}{C_{r s}} \cdot \frac{C_{r x}}{C_{r o}}\left[0,087935 .\left(F_{y i}\right)^{0,79008}\right. \\
\left.-0,005277\left(F_{z i}\right)\right]
\end{array}
$$

where $F_{y i}$ is the lateral force of the tire, $F_{z i}$ is the normal tire force, 0.3 is the current tire modification coefficient, $P$ is the actual tire pressure, and $P_{s}$ is the tire standard pressure $(25 \mathrm{psi})$. The coefficients can be calculated with,

$$
\begin{aligned}
C_{r p} & =3,35+5,30(P)-0,0916(P)^{2} \\
C_{r s} & =3,35+5,30\left(P_{s}\right)-0,0916\left(P_{s}\right)^{2} \\
C_{r x} & =\left[\frac{F_{y \alpha i}+0,107927 . F_{x}}{161,1398}\right] \frac{1}{0,47988} \\
C_{r o} & =\left[\frac{F_{y \alpha i}}{161,1398}\right]^{0,47988}
\end{aligned}
$$

After obtaining the value of the vehicle slip angle, the understeer coefficient $\left(K_{u s}\right)$ for the turning behavior of the vehicle can be calculated by:

$$
\begin{gathered}
R_{n}=\frac{l_{f}+l_{r}}{\delta_{f}+\alpha_{r}-\alpha_{f}} 57,29 \\
K_{u s}=\left(\alpha_{f}{ }^{o}-\alpha_{r}^{o}\right) \frac{R . g}{V^{2}}
\end{gathered}
$$

After getting the $K_{u s}$, the turning behavior of the vehicle can be determined by the following conditions:

(a) $K_{u s}=0$, neutral vehicle.

(b) $K_{u s}=+$, understeer vehicle.

(c) $K_{u s}=-$, oversteer vehicle.

\section{Result and Discussion}

From data collection and calculations, the following design results are obtained.

\subsection{Specification of Vehicle}

Vehicle data and specifications [6] can be seen in Table 1. Before calculating the data, the assumption of the coefficients and the electrical component efficiencies for the study based on the data collection and simulation need to be determined. In this study, we use 0.5 and 2.21 $\mathrm{m}^{2}$ for drag coefficient value and frontal area based on Solidwork simulation and projection. Then we use 0.83 
as transmission efficiency [7], 0.94 as electric motor efficiency [8], 0.95 as battery efficiency [9], and we assume the value of power control efficiency same as the battery.

Table 1. Toyota Calya E M/T Specification

\begin{tabular}{cc}
\hline Type & Value \\
\hline Wheelbase $(\mathrm{mm})$ & 2525 \\
1st gear & 3.417 \\
2nd gear & 1.96 \\
3rd gear & 1.25 \\
4th gear & 0.917 \\
5th gear & 0.707 \\
Final drive ratio & 5.077 \\
Crub weight $(\mathrm{kg})$ & 981 \\
Wheel radius $(\mathrm{mm})$ & 280 \\
\hline
\end{tabular}

\subsection{Toyota Calya ICE Performance}

To calculate the performance of the Toyota Calya ICE as the reference for designing the performance of the Toyota Calya battery electric vehicle (BEV). The maximum climb-ability and maximum speed that can be achieved for ICE version through the following traction plot as shown in Figure 4.

The graph above shows the traction force that can be transmitted using the 3NR-FE engine. It was found that the maximum climb-ability and maximum speed that the Toyota Calya ICE are $25^{\circ}$ and $136 \mathrm{~km} / \mathrm{h}$. This values becomes a design reference for electric vehicle for performing comparable value.

\subsection{Electric Motor Selection}

Assuming the curb weight of vehicle is $1270 \mathrm{~kg}$, the total resistive force of the vehicle can be obtained. Using the total resistive force, the value of the power needed to counter the drag for each slope and the speed were were obtained as shown in Figure 5 .

Based on the graph, it is known that to reach the maximum speed of vehicle to drive on the flat road is 136 $\mathrm{km} / \mathrm{h}$ and it requires $48.99 \mathrm{~kW}$ of power. With a drivetrain efficiency value of 0.83 , the minimum power that electric motor must generate is $59.02 \mathrm{~kW}$. Then the Brog Warner electric motor was selected with type of BLDC HVH250-90 has a power of $60 \mathrm{~kW} 300$ Volts. The choice of BLDC motor is based on its efficiency, which is the best among other motor types, the value of the power per mass is greater, and the power is better because of brushless technology compared to other motors [10]. The maximum torque that can be generated is 330 N.m, the base speed is 1800 $\mathrm{rpm}$, and the maximum speed is $10,600 \mathrm{rpm}$. The voltage for this motorbike is $300 \mathrm{~V}$ and the efficiency is 0.94 .

\subsection{Analysis of Ratio and Transmission Rate}

After determining the specification of electric motor, the transmission ratio is needed in order to reach designed performance. To be able to reach the maximum slope, a first transmission ratio of 1.83 is required. Meanwhile, to reach the maximum speed, a second transmission ratio of 0.707 is needed so the vehicle can reaches the maximum speed. The use of two transmission ratio meets the performance requirements of the vehicle.

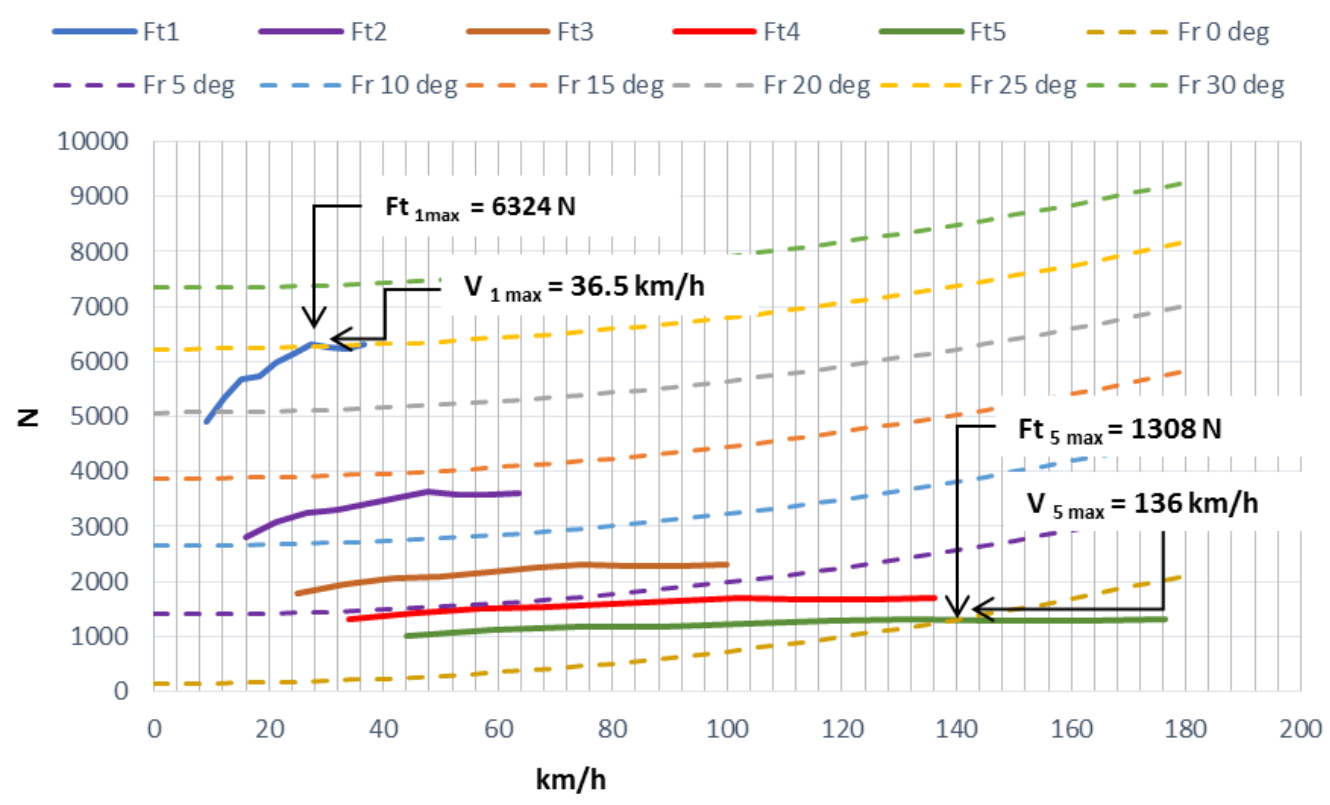

Figure 4. Traction characteristic of Toyota Calya ICE 


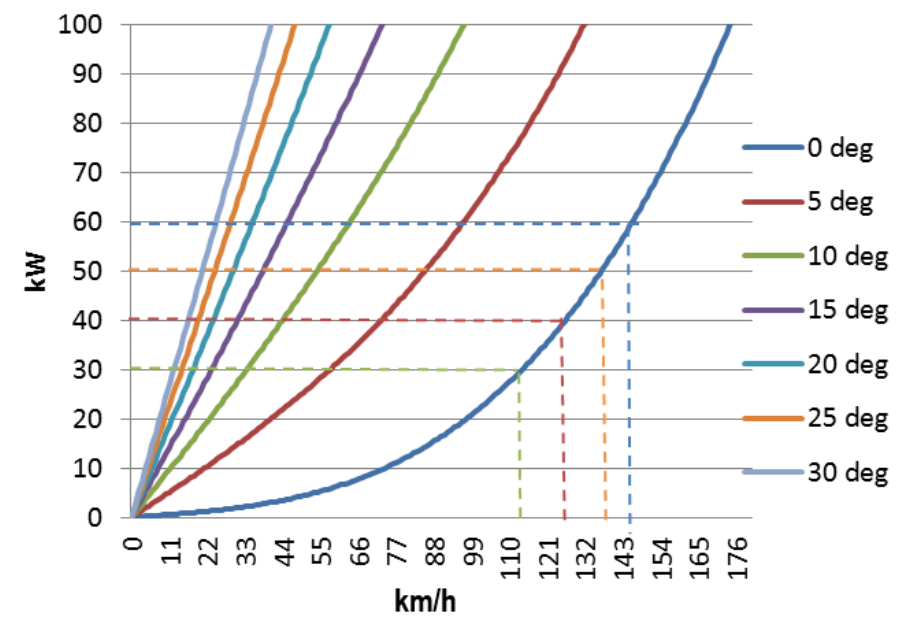

Figure 5. The road horse power requirements of the electric vehicle

\subsection{Analysis of Vehicle Traction Characteristics}

The traction characteristics of the Toyota Calya electric vehicle obtained from calculation is as shown in Figure 6.

From the figure above, we know that by the transmission ratio 1 is able to provide a maximum traction force of $9047 \mathrm{~N}$ and a minimum traction of $1425 \mathrm{~N}$, while in the second level transmission the maximum traction force that transmitted is $3501 \mathrm{~N}$ and the minimum traction is 551 $\mathrm{N}$. Also the first transmision provides a thrust to counter the drag force with maximum of $30^{\circ}$, with a maximum speed of about $20.54 \mathrm{~km} / \mathrm{h}$, and has a maximum speed of $120.98 \mathrm{~km} / \mathrm{h}$ when it reaches maximum rotation on a flat road. Then for transmission 2 , it is able to provide a thrust against a maximum drag of $10^{\circ}$, with a maximum speed of $53 \mathrm{~km} / \mathrm{h}$, and has a maximum speed of $136 \mathrm{~km} / \mathrm{h}$ on flat roads.

Based on the figure, the traction force which is constant until the base speed then decreases to the maximum rpm due to the characteristic torque value provided by the electric motor. The value of the torque of the electric motor is constant up to the base speed, then decreases to its maximum speed. From the results of the re-design using 2 levels of transmission has statify performance.

\subsection{Analysis of Vehicle Power Characteristics}

The power characteristics of the Toyota Calya electric vehicle is shown in Figure 7

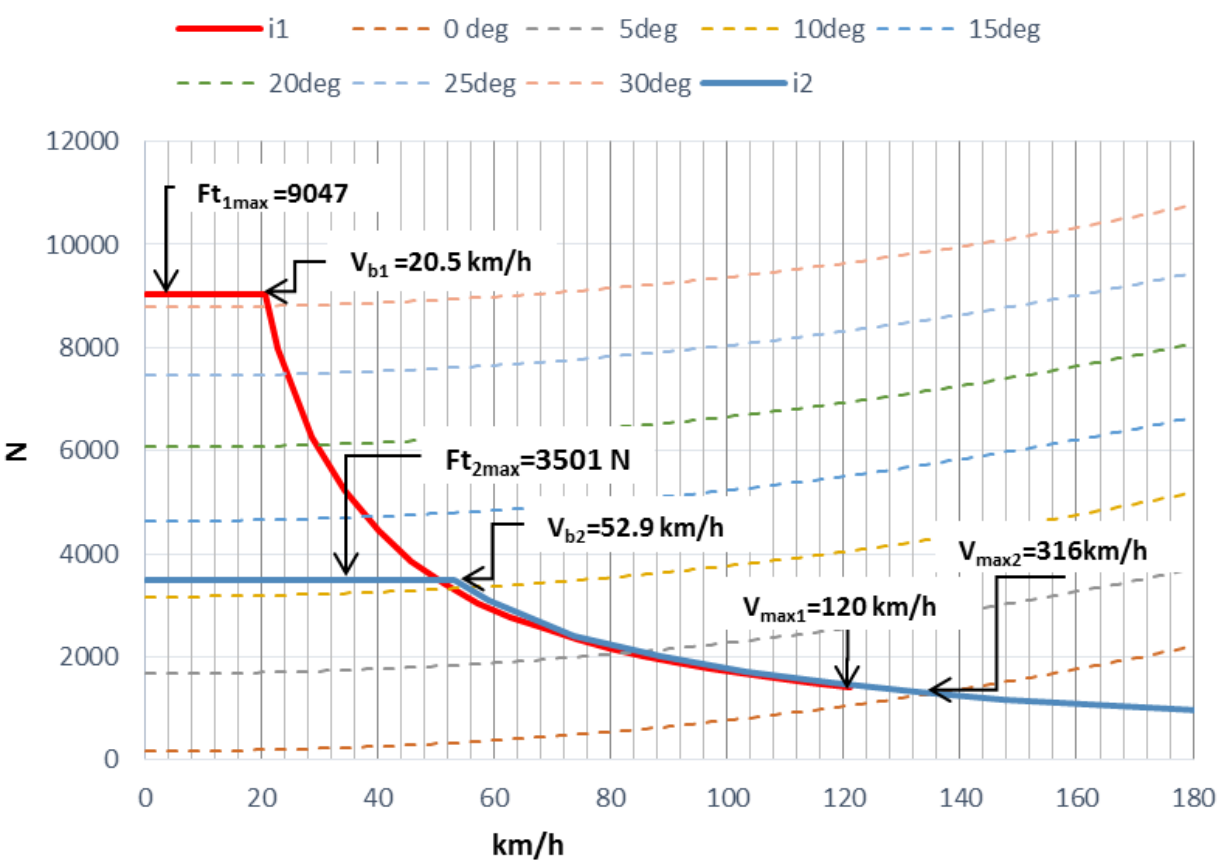

Figure 6. Traction characteristic of electric vehicle using 2 speed transmission 


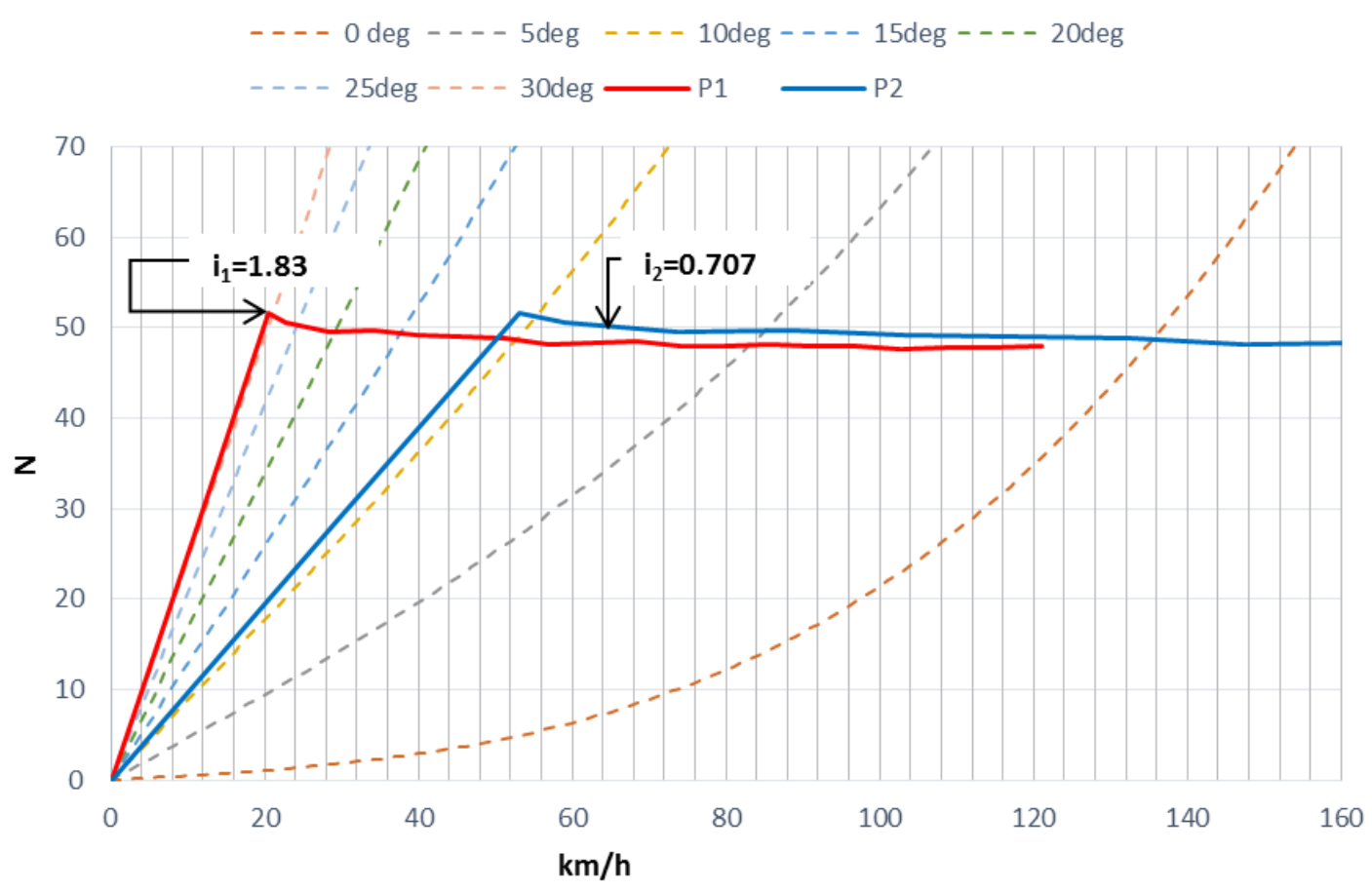

Figure 7. Power characteristic of 2-speed electric vehicle

From the figure above, the power characteristics of the electric Toyota Calya shown. In the first transmission, the power generated is only able to reach at a maximum slope of $30^{\circ}$, and has a linear trendline from $0 \mathrm{rpm}$ to its base speed until $1800 \mathrm{rpm}$. The maximum speed that can be reached at is $20.54 \mathrm{~km} / \mathrm{h}$ and $120.98 \mathrm{~km} / \mathrm{h}$ on the flat road. Meanwhile the second transmission can reach a maximum speed of $53.08 \mathrm{~km} / \mathrm{h}$ at angle of $10^{\circ}$ and 136 $\mathrm{km} / \mathrm{h}$ on a flat road. This power characteristics is suitable with the traction characteristics. The maximum power that can be transmitted in the first and second transmissions is $51.62 \mathrm{~kW}$, while the minimum power is $47.9 \mathrm{~kW}$. The decrease in power transmitted from the electric motor to the driving wheels is due to the efficiency of the transmission.

\subsection{Energy Consumption}

While analyzing energy consumption, a driving cycle is needed to find out how much energy is needed for accelerating. With the power values of the Toyota Calya ICE and Toyota Calya BEV of $77.068 \mathrm{~W}$ and $60,000 \mathrm{~W}$, and the mass of the ICE and BEV vehicles of $981 \mathrm{~kg}$ and $1270 \mathrm{~kg}$, the WLTP class 3 driving cycle was chosen for both types of vehicles to be calculated. The vehicles are considered driving on a horizontal road so the gradient resistive force is zero. After getting the speed each time on one driving cycle, the road power value is obtained as shown in Figures 8

From the road horse power for each type of vehicle, then the value of acceleration power used to calculate the amount of energy used for acceleration. The energy used during acceleration, which is the area of the graph, were calculated using the trapezodial method. After calculating, the energy consumption of the Toyota Calya ICE vehicle is $0.539 \mathrm{~kW} . \mathrm{h} / \mathrm{km}$, while the energy consumption for the Toyota Calya BEV vehicle is $0.431 \mathrm{~kW} . \mathrm{h} / \mathrm{km}$. It is known that the value of electrical energy consumption is 0.108 $\mathrm{kW} . \mathrm{h} / \mathrm{km}$ lower than the Toyota Calya ICE. This is because there its larger losses from the engine. So that the energy consumption value of the Toyota Calya ICE, even though the vehicle is lighter, becomes greater than the Toyota Calya BEV.

\subsection{Battery Requirement}

The battery requirement is obtained by the energy consumption and the desired mileage. In this study, the Toyota Calya BEV battery energy is needed to be able to travel a distance of $85 \mathrm{~km}$. The choice of value is based on a Chevy electric vehicle that can reach a distance of $85 \mathrm{~km}$. Based on the calculation, the minimum power required by the vehicle is 36,639 kW.h. To fit the battery with the lightest mass possible, a Li-ion type battery is chosen because it has a high specific density of 150 - 190 W.h $/ \mathrm{kg}$. In addition, the Li-ion battery has low toxicity and a high life cycle. From the research, it was found that the LG CHEM $60.1 \mathrm{~V}$ and $2.6 \mathrm{~kW} . \mathrm{h}$ Li-ion Polymer battery. Due to the motor voltage requirement of $300 \mathrm{~V}$ and the minimum energy required of $36,639 \mathrm{~kW} . \mathrm{h}$, it takes 3 batteries arranged in parallel and 5 batteries arranged in series to get the required motor capacity of $122.13 \mathrm{~A}$.h and the voltage is $300 \mathrm{~V}$. So the total number of Li-ion Polymer battery needs are 15 batteries so the energy obtained is $39 \mathrm{~kW}$. 


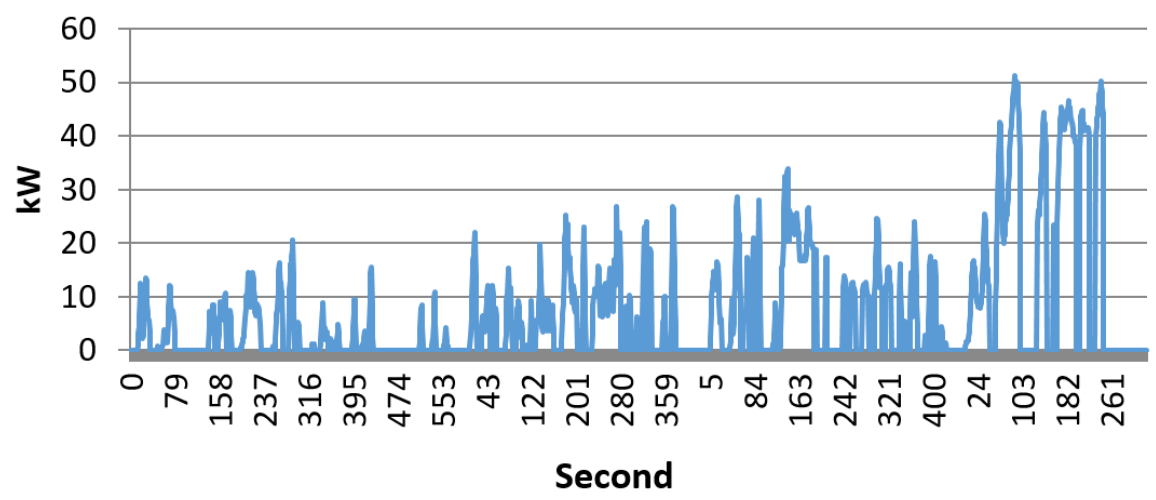

(a)

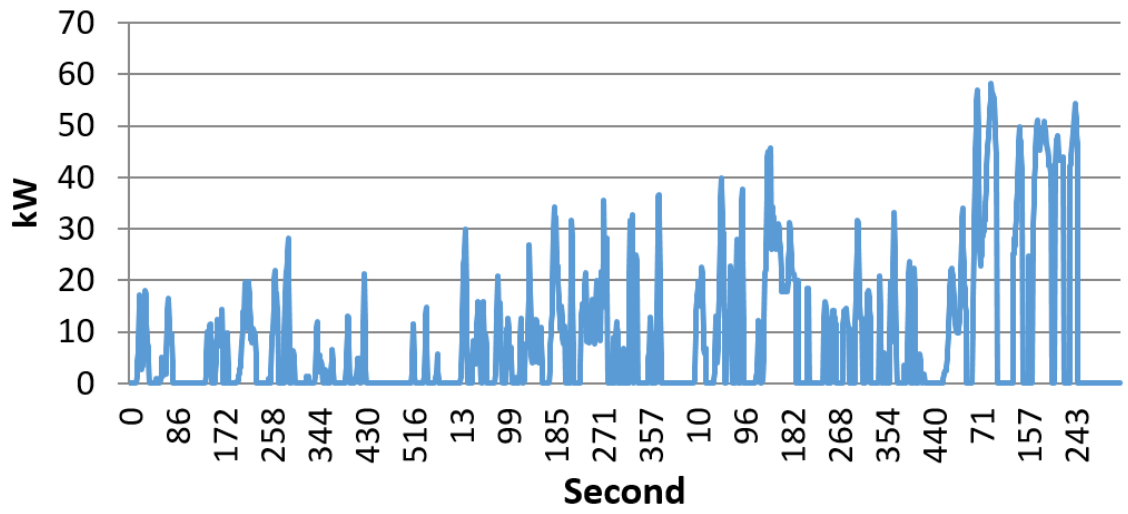

(b)

Figure 8. The road horsepower acceleration generated on: (a) ICE (b) BEV

\subsection{Vehicle Turning Behavior}

The turning behavior of the vehicle in this study is carried out with the maximum speed value for the skid and the slip angle that occurs. Before calculating the skid speed and slip angle, the center of gravity (CG) point calculation is carried out for the Toyota Calya ICE and Toyota Calya BEV vehicles. In this study, we use the following CG value based on the Table 2 .

Table 2. Center of gravity for each vehicle type

\begin{tabular}{cc}
\hline Type & Point location \\
\hline a CG 1 & $1.261 \mathrm{~m}$ \\
b CG 1 & $1.264 \mathrm{~m}$ \\
a CG 2 & $1.345 \mathrm{~m}$ \\
b CG 2 & $1.180 \mathrm{~m}$ \\
\hline
\end{tabular}

The center of gravity used in the study based on the weighing results and components placement with 5 passengers. CG 1 determines Toyota Calya ICE center of mass, while CG 2 determines Toyota Calya BEV with 3 batteries are placed in front of the car (hood), and another 12 batteries placed in the fuel tank space. From CG 1 is the center of mass of the Toyota Calya ICE, CG 2 is the center of mass of the Toyota Calya BEV, the skid speed graph is obtained as shown in Figure 9

From this graph, the maximum speed for experiencing skids is obtained from the greatest values that are CG 1 then the lowest speed limit is CG 2. Based on the comparison of the speed limit of the front wheel skid and the rear wheel, CG 1 tends to experience understeer because $V_{s f}<V_{s r}$, while CG 2 tend to experience skid overteer. From the results of the slip angle, the understeer coefficient (Kus) value for the three CG positions and variations in the turning speed of the vehicle are obtained as shown in Figure 10 .

From the results of Kus, it was known that CG1 has a maximum Kus value at a speed of $20 \mathrm{~km} / \mathrm{h}$ of 0.039 , while CG 2 is 0.059. It is known that all three CG positions are neutral and understeer for both vehicle. From the maximum skid speed limit and the Kus, it is known that CG 1 has an understeer tendency due to the skid speed of the front and rear wheels that meet the conditions of $V_{s f}<V_{s r}$, the Kus has positive value so it is the safest to drive. Meanwhile, from the configuration of the Toyota Calya BEV based on the skid speed and Kus, it was found that CG 2 has an oversteer behavior at the certain turning angle yet the Kus value that is still in positive value so it is safer to drive while driving turning under the maximum skid speed limit. 


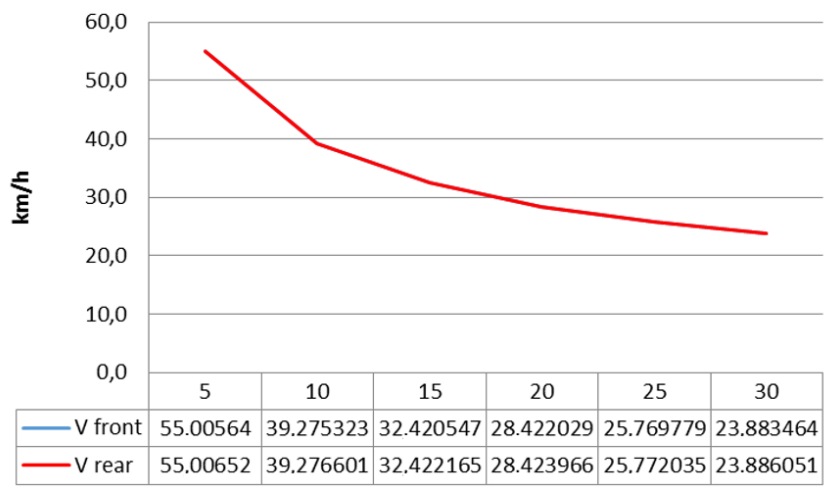

(a)

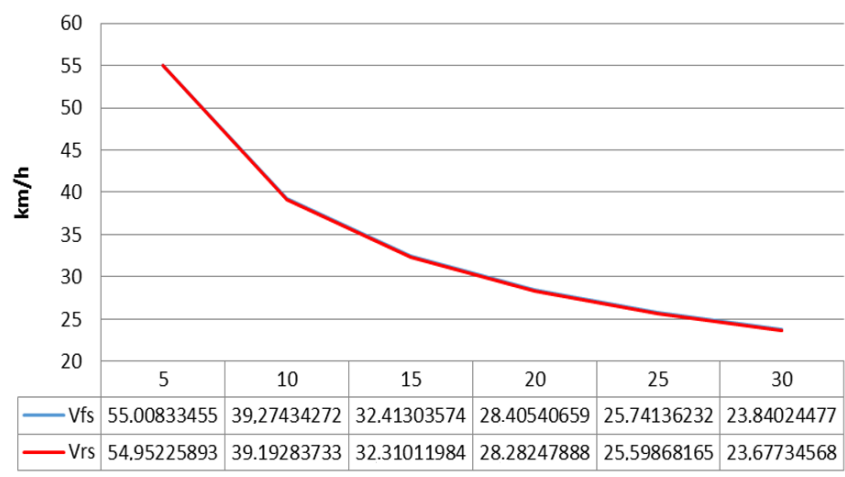

(b)

Figure 9. Maximum skid speed of: (a)CG 1 (b) CG2

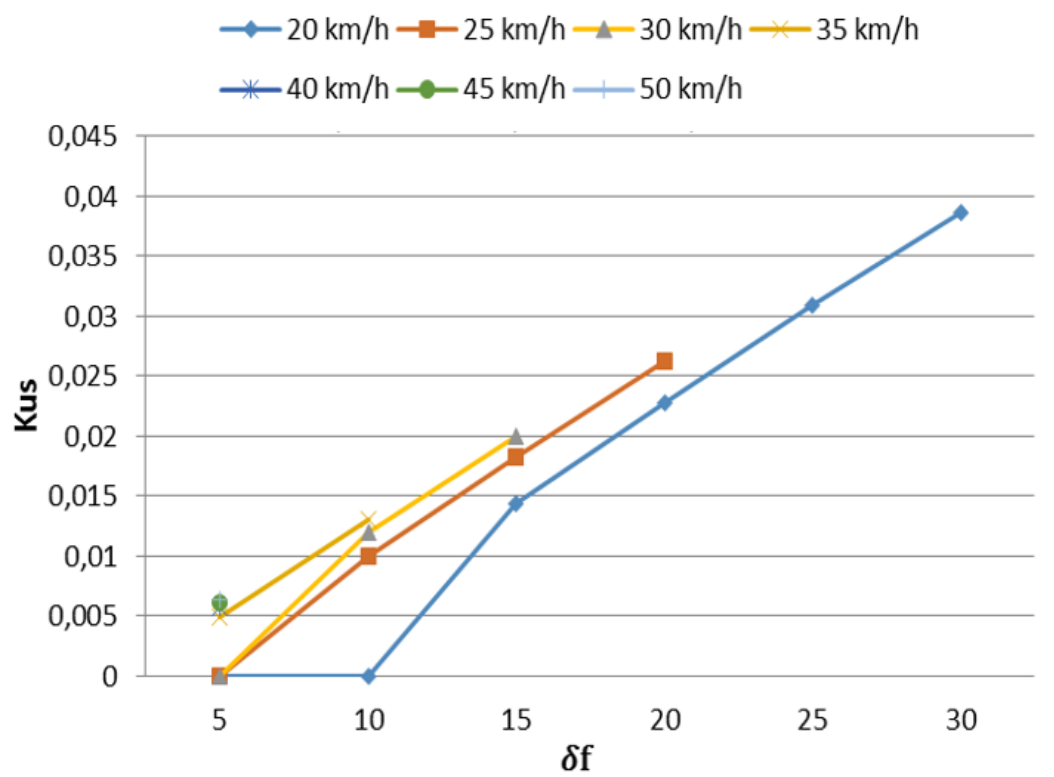

(a)

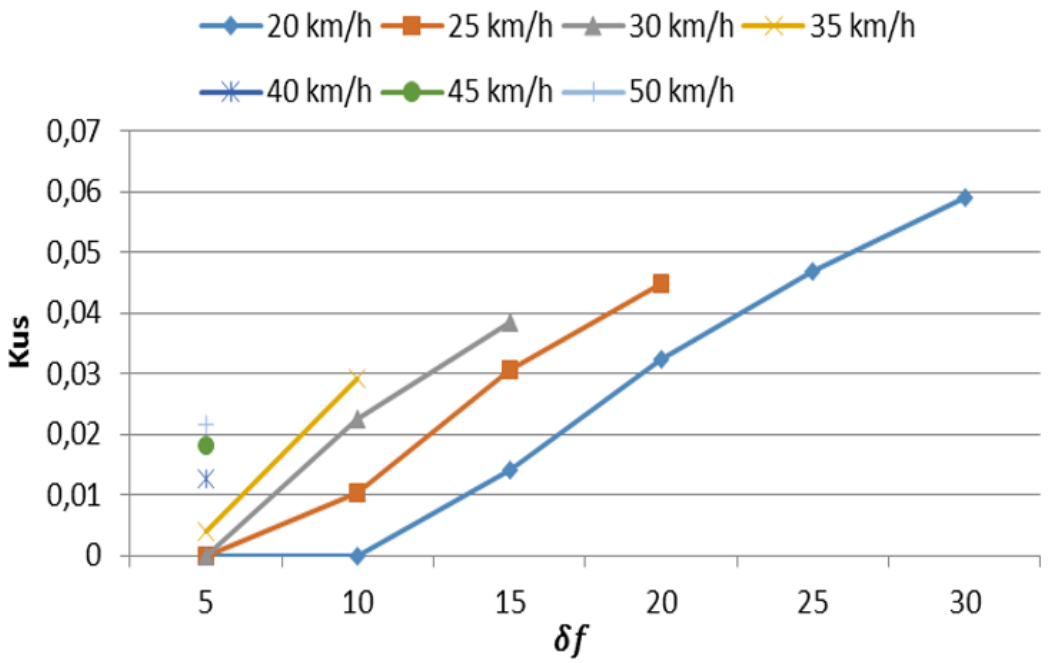

(b)

Figure 10. The Kus value of: (a)CG 1 (b) CG2 


\section{Conclusions}

The conclusions of this research are the BLDC motor type HVH250-90 $60 \mathrm{~kW}$ is suitable as a driving source and the 2-speed transmission ststify the performance with the first ratio of 1.83 and the second ratio of 0.707 . The Toyota Calya BEV can reaches the climb-ability of $30^{\circ}$ and a maximum speed of $136 \mathrm{~km} / \mathrm{h}$ on flat roads, while the Toyota Calya ICE can climb $25^{\circ}$ and have a same maximum speed as BEV. The energy consumption for WLTP driving cycle of the electric vehicle is $0.431 \mathrm{~kW} . \mathrm{h} / \mathrm{km}$, while the energy consumption of the ICE is $0.539 \mathrm{~kW} . \mathrm{h} / \mathrm{km}$ due to the component efficiency. The battery used is the LG Chem Li-Ion Polymer 60.1 V, 43 A.h battery with 15 batteries arranged in buddy-pair series as a power source from the vehicle because it has better specific energy among the other and less toxic. Based on the turning behavior, Toyota Calya ICE has the best stability because of mostly understeer turning behavior, however the driver must be careful when turning the electric car due to the speed limit for not experiencing the oversteer.

\section{Acknowledgments}

The researchers thank Pusat Unggulan Iptek dan Sistem Kontrol Otomotif Sepuluh Nopember Institute of Technology Surabaya for supporting and providing the data in this stud, also the lecturers of Sepuluh Nopember Institute of Technology who help the researcher to enhance the quality of journal.

\section{References}

[1] GAIKINDO, "10 mobil terlaris di indonesia juli 2019," https://www.gaikindo.or.id/10-mobil-terlarisjanuari-oktober-2019-honda-brio-geser-mitsubishi- xpander/. (accessed on 2 June 2020).

[2] Enerdata, "Data inventory emisi grk sektor energi, badan pusat data dan teknologi informasi energi dan sumber daya mineral kementerian esdm," 2018.

[3] I. N. Sutantra, "Teknologi otomotif hybrid," 2015.

[4] N. Roman, "Car engineer," https://carengineer.com/the-different-driving-cycles/. (accessed on 1 May 2020).

[5] W. Gołębiewski and M. Lisowski, "Theoretical analysis of electric vehicle energy consumption according to different driving cycles," in IOP Conference Series: Materials Science and Engineering, vol. 421, p. 022010, IOP Publishing, 2018.

[6] Toyota Calya, https://toyota.astra.co.id/product/calya/. (accessed in 16 February 2020).

[7] "Finding the car center of gravity/mass," http://www.thecartech.com/. (acessed in 7 March 2020).

[8] "Borg warner lt.d," https://www.brogwarner.com/technologies/electricdrive-motors/hvh-series-electric-motor/. (accessed in 17 April 2020).

[9] bigbattery.com Big Battery, https://bigbattery.com/product/60v-lg-chembattery-module/. (acessed 9 July 2020).

[10] P. Bhatt, H. Mehar, and M. Sahajwani, "Electrical motors for electric vehicle-a comparative study," Proceedings of Recent Advances in Interdisciplinary Trends in Engineering \& Applications (RAITEA), 2019. 